\title{
COMPARATIVE ANALYSIS FOR METHODS OF BUILDING DIGITAL ELEVATION MODELS FROM TOPOGRAPHIC MAPS USING GEOINFORMATION TECHNOLOGIES
}

\author{
Vadim BELENOK (D1*, Yuriy VELIKODSKY (i) ${ }^{1}$, Oleksandr NIKOLAIENKO®1, \\ Nataliia RUL ${ }^{1}$, Sergiy KRYACHOK ${ }^{(12}{ }^{2}$, Tetiana MALIK (D)3 \\ ${ }^{1}$ Aerospace Geodesy and Land Management Department, National Aviation University, Kyiv, Ukraine \\ ${ }^{2}$ Educational-Scientific Institute of Construction Chernihiv National University of Technology, Chernihiv, Ukraine \\ ${ }^{3}$ Geodesy, Land Management and Ecology Department, University of Emerging Technologies, Kyiv, Ukraine
}

Received 19 July 2019; accepted 29 October 2021

\begin{abstract}
The article considers the question of estimating the accuracy of interpolation methods for building digital elevation models using Soviet topographic maps. The territory of the Kursk region of the Russian Federation was used as the study area, because it is located on the Central Russian Upland and characterized by the complex structure of the vertical and horizontal dissection of the relief. Contour lines automatically obtained using a Python algorithm were used as the initial elevation data to build a digital elevation model. Digital elevation models obtained by thirteen different interpolation methods in ArcGIS and Surfer software were built and analyzed. Special attention is paid to the ANUDEM method, which allows to obtain hydrologically correct digital elevation models. Recommendations for the use of one or another method of interpolation are given. The results can be useful for professionals who use topographic maps in their work and deals with the design using digital elevation models.
\end{abstract}

Keywords: digital elevation model, interpolation methods, ANUDEM, soviet topographic maps, contours, automatic contours vectorization.

\section{Introduction}

One of the ways to depict the terrain using modern geoinformation technologies (GIT) is to build a digital elevation model (DEM). DEM is a special kind of threedimensional mathematical models, which is a reflection of the "relief" of both real and abstract geofields (surfaces). DEM is the basis of data representation in automated cartography. According to the definition given on the website of the US Geological Survey, DEMs are arrays of regularly spaced elevation values referenced horizontally either to a Universal Transverse Mercator (UTM) projection or to a geographic coordinate system. The grid cells are spaced at regular intervals along south to north profiles that are ordered from west to east (United States Geological Survey, n.d.). In the literature, DEM is also often defined as a regular array of heights counted from any reference surface (Wood, 1996). According to Pivnyak et al. (2014) DEM is a file of elevation values attached to nodes of a rather small regular network and organized in the form of a rectangular matrix, which is a digital expression of elevation characteristics on the topographic map.

DEMs play a fundamental role in the Earth sciences and technology and have many applications. They can be used to calculate derivative values such as volume, slope, curvature, shading of hills, contours, visibility from specified areas, drainage and gravity.

Examples of DEM applications include their use as a base layer in geographic information systems (GIS), for example, for planning engineering structures (roads, railways, canals), hydrology (analysis of drainage and catchment areas), shoreline (flooding), mass movements in mountainous areas, visualization and topographic maps.

GIS uses various interpolation methods to build a DEM from the original data sets. Moreover, all interpolation methods can be divided into two categories: deterministic and geostatistical. Deterministic interpolation techniques can be divided into two groups: global and local. Global techniques calculate predictions using the entire data set. Local techniques calculate predictions from the measured

${ }^{*}$ Corresponding author. E-mail: belenok.vadim@gmail.com 
points within specified neighborhoods, which are smaller spatial areas within the larger study area (Tagelsir, 2010).

1. Deterministic methods of surface interpolation use mathematical functions for interpolation and have no random component. Deterministic methods include:

- global polynomial interpolation;

- local polynomial interpolation;

- Inverse Distance Weighting (IDW);

- radial basis functions;

- kernel interpolation with barriers;

- diffusion interpolation with barriers.

2. Geostatistical methods of interpolation, which are based on mathematical and statistical models that take into account the spatial autocorrelation between reference points. Kriging methods are common in GIS: they are suitable for different data types and have different basic assumptions. There are:

- ordinary Kriging;

- simple Kriging;

- universal Kriging;

- indicator Kriging;

- probability Kriging;

- disjunctive Kriging;

- areal interpolation;

- Empirical Bayesian Kriging.

There are a lot of works on DEM interpolation mothods, particularly in GIS.

The paper (Hutsul \& Smirnov, 2017) considered the possibility of constructing DEMs using soviet topographic maps of different scales in order to estimate the practicality of using such DEMs for road planning. The resulting DEMs are compared to existing ASTER and SRTM models by raster subtraction. The advantage of the work is using the ANUDEM method to construct DEMs, and the disadvantages of the work include the fact that DEMs were constructed using a limited set of elevation data: only using contours and elevation points.

The paper Ajvazi and Czimber (2019) performed a comparative analysis of DEMs constructed by different interpolation methods in GIS. Some interpolation methods are also described in detail. The authors consider three scenarios. The first one includes $10 \%$ of randomly selected control points, the second one includes $20 \%$, and the third one includes $30 \%$. The mean absolute error (MAE) and the root-mean-square error (RMSE) are calculated. The authors conclude that the results obtained do not make much difference, but the most accurate results are obtained from the methods of interpolation "spline" and "kriging". Disadvantages include the use of a small set of elevation data, the lack of the ANUDEM method, and the consideration of a small number of interpolation methods.

The paper Arun (2013) also performed a comparative analysis of DEMs constructed by various interpolation methods in GIS, including the ANUDEM method. Elevation matrix for constructing DEMs by various interpolation methods and control points were obtained using ground-based survey methods. The obtained DEMs were also compared with the SRTM model for India. The author concludes that the kriging method works better than other modern methods in most cases.

The paper Salekin et al. (2018) studies three different deterministic approaches to constructing DEMs: Natural Neighbor, Topo to Raster (ANUDEM) and Inverse Distance Weighting (IDW). GNSS data is used as the elevation matrix. DEMs were interpolated with a spatial resolution in the range of $0.5 \mathrm{~m}$ to $10 \mathrm{~m}$. It was found that the highest resolution $(0.5 \mathrm{~m})$ results in the smallest errors in the obtained DEMs $(\mathrm{RMSE}=0.428 \mathrm{~m}, \mathrm{MAE}=0.274 \mathrm{~m}$ ). The ANUDEM method gave the highest accuracy of building DEMs. The disadvantages of the work include the study of the accuracy of a small number of interpolation methods and the lack of consideration of geostatistical methods at all.

\section{ANUDEM method}

The ANUDEM algorithm is a locally adaptive interpolation approach proposed by Michael Hutchinson at the Australian National University (Hutchinson, 1988). This algorithm uses an interpolation method that is specifically designed to create a surface that more accurately represents the natural drainage surface and preserves both the lines of the ridge and the srteam networks.

The approach uses an iterative method of finite difference interpolation that optimizes the computational efficiencies of local interpolation without losing the continuity of the global interpolation surface. This relief model can be used to determine the hydrographic characteristics of rivers and their basins, as well as for hydrological modeling.

ANUDEM takes into account the special nature of the relief surfaces, as well as the specific points of the surface that can be used to describe the relief. The Topo to Raster model is considered by many studies to obtain hydrologically correct DEMs, for example Curebal et al. (2015), Salari et al. (2014).

DEM is considered hydrologically correct if it satisfies two main requirements (Yakovchenko, 2007):

- there must be no fictitious sink points (fictitious depressions) in the DEM;

- the srteam lines (thalwegs) on the DEM must coincide with the input segments of the river network.

To create a DEM by method ANUDEM one can use a complete set of terrain data obtained from topographic maps. Here are images of terrain data on soviet topographic maps, which were used to build the DEM in this paper.

1. Point elevation data (Figure 1). Point objects that have values of elevation in the attribute table: elevation marks, water edges, control points of the geodetic network. Each file in a common format contains the coordinates $\mathrm{X}, \mathrm{Y}, \mathrm{Z}$, which indicate the position and elevation of each data point. There is no limit to the number of input elevations read from user-provided data files. 
2. Sink point data (Figure 2). A class of point objects that shows known local elevation minimums. The elevation of the point can be left undetermined by setting the value of $\mathrm{Z}$, which lies outside the user-defined limits (for example, -999.0).

3. Streamline data (Figure 3). Linear objects representing a network of watercourses (rivers, streams, drying watercourses). All arcs must be oriented downstream. The coordinate pairs in each stream must be ordered from the highest point to the lowest.

4. Coastline data (Figure 4). Class of polygonal spatial objects containing the outlines of the coastline. Pixels in the final output raster, located outside these polygons, are assigned a value less than the user-specified minimum elevation limit.

5. Contour line data (Figure 5). Linear objects (main and additional contour lines) that contain elevation values in the attribute table. The table must contain the coordinates and elevation of the contour. Isolines that connect to isolines with different elevations are marked in the error file.

6. Lake boundary data (Figure 6). A class of polygonal spatial objects that determine the location of lakes. All pixels of the output raster that located inside the lake are
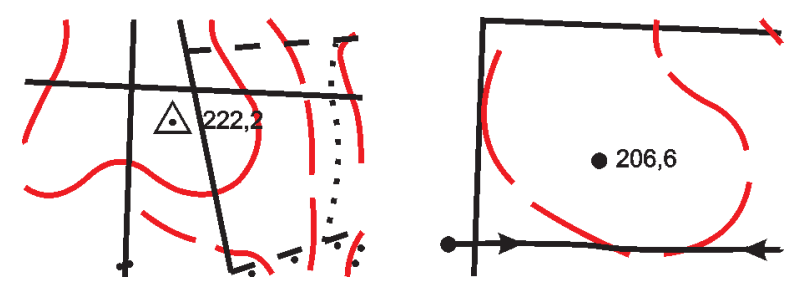

Figure 1. Point elevation data

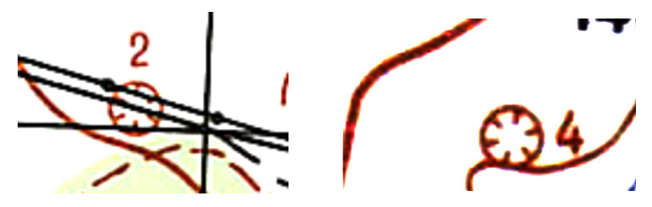

Figure 2. Sink point data
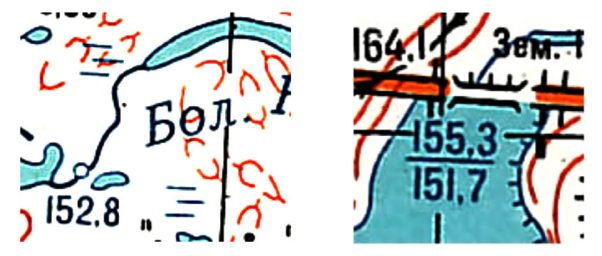

Figure 3. Streamline data
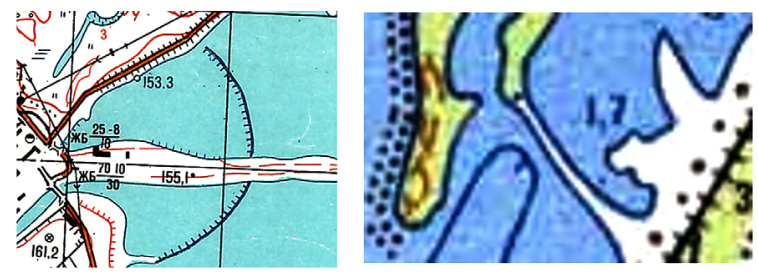

Figure 4. Coastline data assigned the minimal elevation value of all pixels located along the shoreline.

7. Cliff line data (Figure 7). Linear objects representing cliffs. The cliff objects should have a direction, so that the left side of the line corresponds to the lower side of the cliff.

8. Exceptions (Figure 8). Polygonal objects that are areas excluded from the interpolation process. Most often used to exclude data related to dams and bridges.

The paper Tan and Xu (2014) estimated the accuracy of DEM built by the ANUDEM method. As a result, the following values were obtained:

- for hilly terrain: MAE $=2.704 \mathrm{~m}, \mathrm{RMSE}=5.864 \mathrm{~m}$ :

- for mountainous terrain: $\mathrm{MAE}=5.918 \mathrm{~m}, \mathrm{RMSE}=$ $7.083 \mathrm{~m}$ :

The obtained errors are the smallest among the interpolation methods studied: Kriging, Inverse Distance Weighting, Spline Interpolation, Natural Neighbor, TIN.

ANUDEM was used to develop 9 arc-second DEM of Australia (ANU Fenner School of Environment and Society and Geoscience Australia, 2008), which in turn was used to produce the map of drainage basins and groundwater for the Australian continent (Stein, 2006).
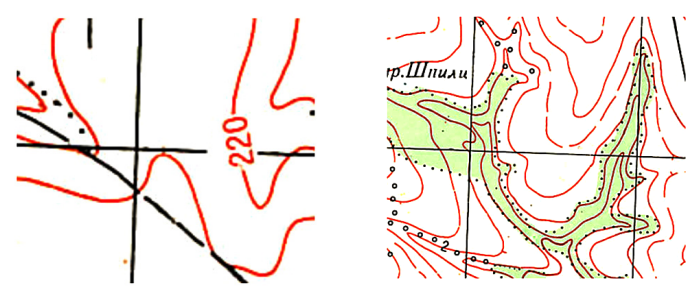

Figure 5. Contour line data
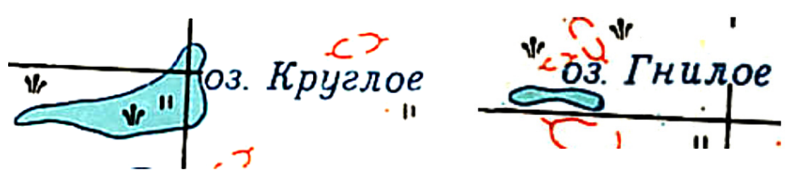

Figure 6. Lake boundary data
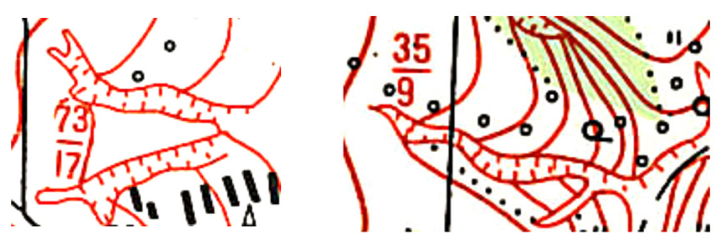

Figure 7. Cliff line data
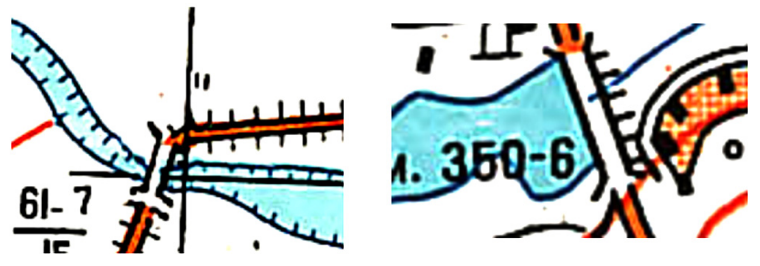

Figure 8. Exceptions 
Advantages of using the ANUDEM method:

- it quickly processes various types of data in the form of points, lines;

- the possibility of using to determine the hydrographic characteristics of rivers and their basins;

- the amount of input data can be an order of magnitude less than is usually required for an adequate description of the surface with digitized contour lines;

- the obtained DEMs have small errors relative to other methods.

Let us consider the algorithm used in the ANUDEM method. The method allows to create a DEM by interpolating the values of elevations by imposing constraints that provide a connected drainage structure and correct representation of ridges and flows based on the input data of contour lines (Shihov et al., 2017). During interpolation, at each iteration of the algorithm, depressed terrain areas are found on watersheds, saddles, ravines and are assigned to surface sink lines. The method is based on calculating the values of the interpolated function using the following expression:

$$
z_{i}=f\left(x_{i}, y_{i}\right)+\varepsilon_{i},
$$

where $f$ is an unknown suitably smooth bivariate function of horizontal location represented as a finite difference grid; $i=(\overline{1 ; n}), n$ is the number of data points; $\varepsilon_{i}$ is a zero mean error term with standard deviation $w_{i}$. For accurately surveyed elevation data, the standard deviation is dominated by the natural discretisation error of the finite difference representation of $f$ (Hutchinson et al., 2009).

Each reference point is located, as a rule, randomly, and the standard deviation of discretisation error for each pixel of the raster model is calculated by formula

$$
w_{i}=\frac{h v_{i}}{\sqrt{12}},
$$

where $v_{i}$ is the local slope angle in the pixel, $h$ is the pixel size.

The function $f$ is then estimated by solving for the regular grid finite difference approximation to the bivariate function $f$ that minimises:

$$
\sum_{i=1}^{n}\left[\frac{z_{i}-f\left(x_{i}, y_{i}\right)}{w_{i}}\right]^{2}+\lambda J(f),
$$

where $J(f)$ is a measure of the roughness of the function $f$ in terms of first and second derivatives (Hutchinson, $1989), \lambda$ is a positive number called the smoothing parameter. The smoothing parameter $\lambda$ is usually chosen so that the weighted residual sum of squares in is equal to $n$. This can be achieved using the approximate Newton-Rhapson method in combination with an iterative solution. Spatially varying weights in the residual sum of squares in are a locally adaptive indication that can only be achieved using the iterative interpolation method, for which the slopes in the grid cells are available as the iterative solution is executed. (Hutchinson et al., 2009).

The iterations are finished when the user-specified maximum number of iterations is reached (usually 20). Upon completion of iterations, the program calculates all the sink points remaining in the grid, and saves the detailed report in the output log file. The remaining sink points are written to the output file to plot for detecting and correcting input errors. The current data included in the grid and other diagnostics are also written to the output diagnostic files of points and rows for further estimating the accuracy of the grid building process.

\section{Methodology}

To build the DEM, three soviet topographic maps of the Kursk region of the Russian Federation were used. The

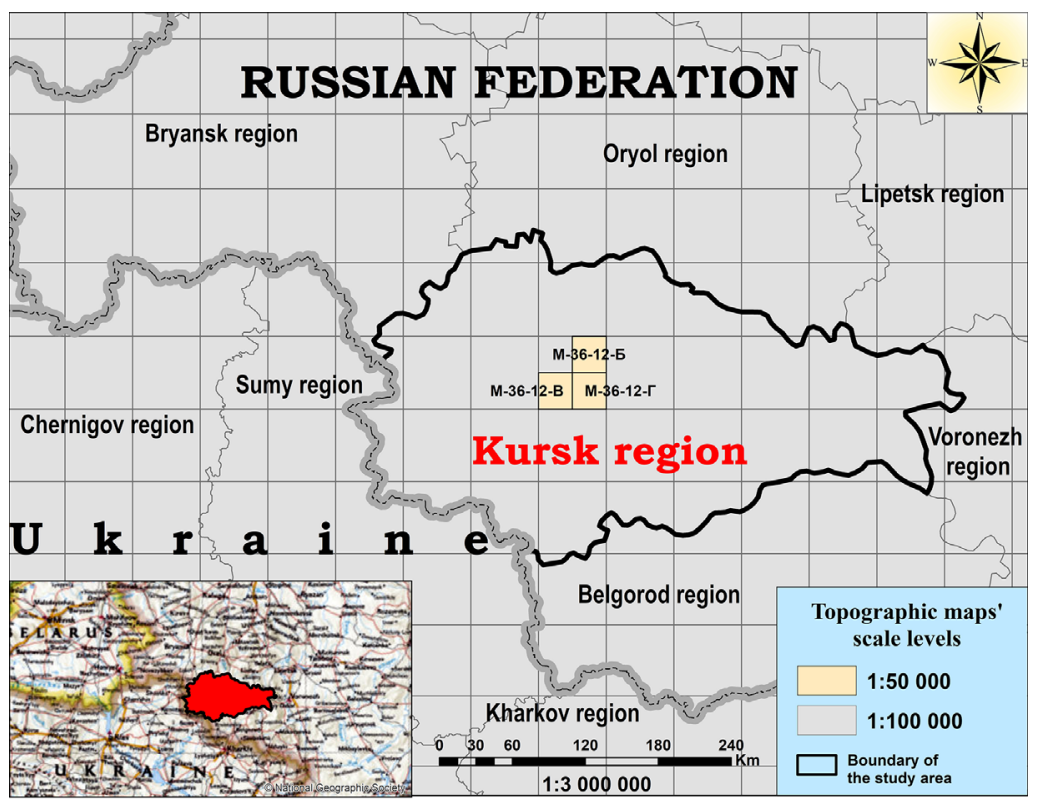

Figure 9. The location of the study area on the trapezoids of soviet topographic maps 


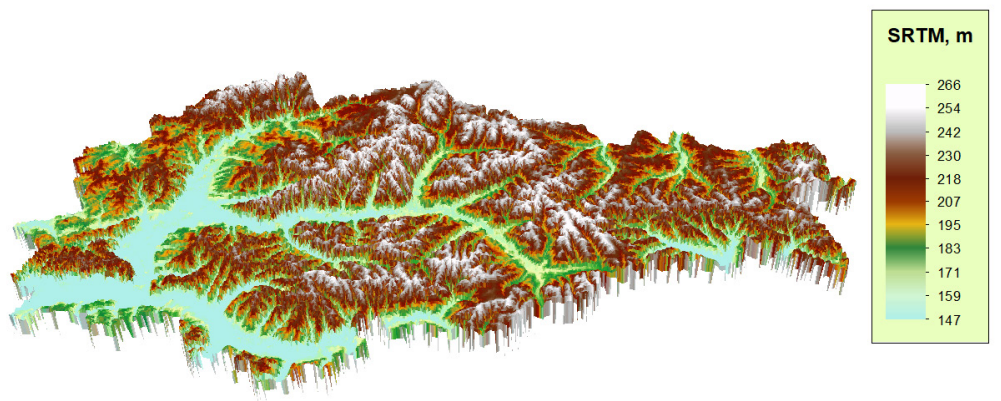

Figure 10. DEM of the Kursk region obtained as a result of the SRTM mission
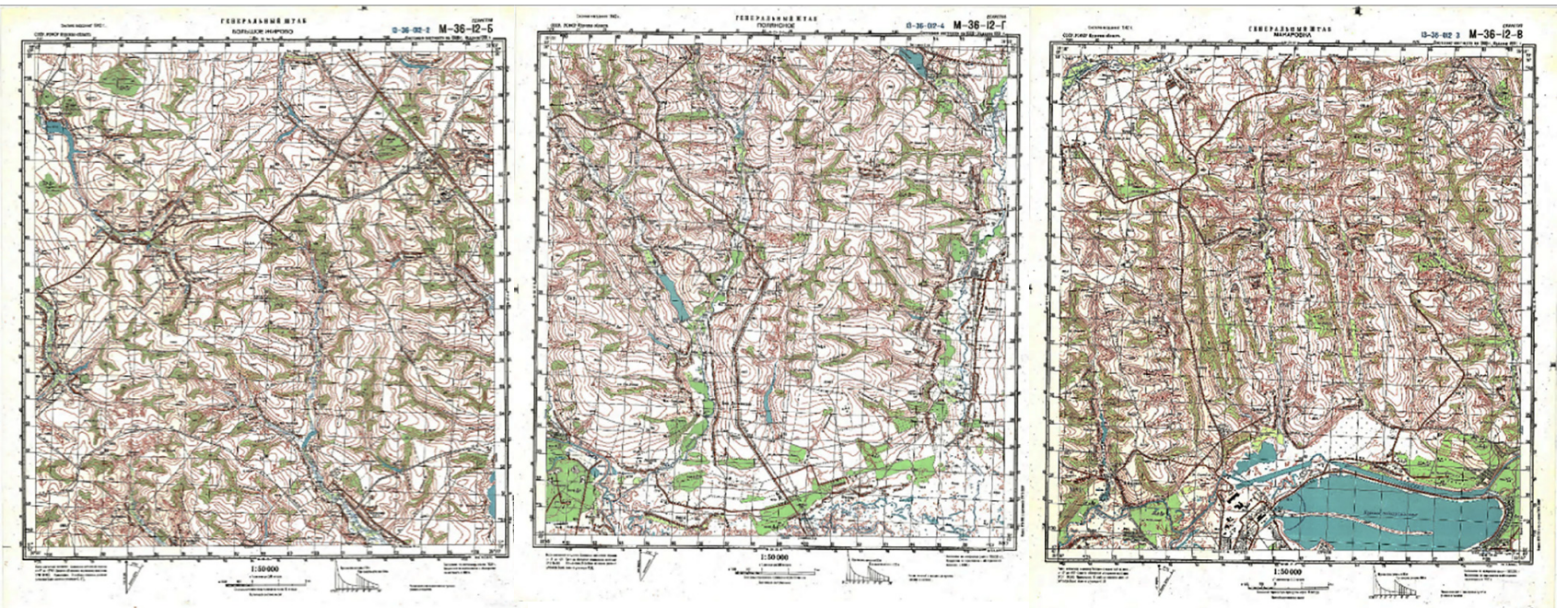

Figure 11. Sheets of soviet topographic maps for the study area

Kursk region is located between $50^{\circ} 54^{\prime}$ and $52^{\circ} 26^{\prime}$ north latitude and $34^{\circ} 05^{\prime}$ and $38^{\circ} 31^{\prime}$ east longitude on the border with Ukraine. The territory of the Kursk region is located on the southwestern slopes of the Central Russian Upland. The elevation of the surface above sea level is mainly $175-225 \mathrm{~m}$. The central part of the region is the most elevated. The general slope of the terrain goes from northeast to southwest. The DEM of the Kursk region obtained from the SRTM mission and downloaded from the resource (EarthExplorer, n.d.) is shown in Figure 10. Figure 9 and Figure 10 were created using geographic information technology as described in Liashenko et al. (2020).

The input data for building the DEM were three sheets of soviet topographic maps at a scale of 1: 50000 , covering the area of interest, the nomenclature M-36-12-6, M-36-12-в, and M-36-12-г (Figure 11). The maps used the Baltic Sea vertical datum of 1977 , contours were drawn for every $10 \mathrm{~m}$.

To build a DEM, the maps were scanned, and automated digitization of contour lines was performed according to the algorithm described in Rul et al. (2018).

At the first step, Python script read a fragment of the map using the NumPy library and create three arrays with brightness values in the channels R, G, B. Then the images are converted into a color model HSV (Hue, Saturation, Value): a new array is created, which is filled with the calculated HSV values. At the next stage of the algorithm, the classification by HSV values is performed. To do this, we manually select ranges for each of the three HSV parameters, that correspond to the color of the contour lines, by analyzing a specific scan of the topographic map. A map of contour lines is created, in which the values of 1 are assigned to pixels that fall into the ranges for all HSV parameters, and the remaining pixels are assigned the value 0 . As a result of the above steps, we automatically get the contours shown in Figure 12, which also shows the rest of elevation information, which was obtained by

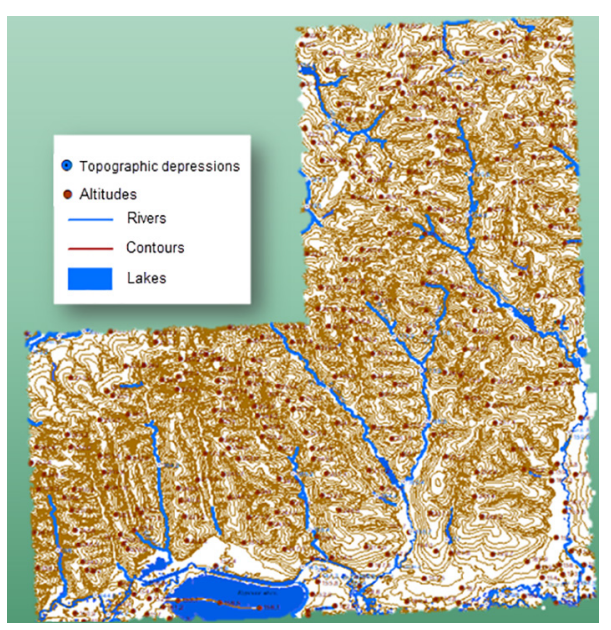

Figure 12. Scanned layers of elevation data 
digitization of soviet topographic maps in the ArcGIS software environment.

At the next step in building a DEM, we select a pixel size, which is usually set to approximately $0.5 \mathrm{~mm}$ on the map scale. Therefore, the pixel size of the DEM was set to $25 \mathrm{~m}$. When using larger values, the DEM would be smoother and would not accurately reproduce the original elevation data.

The ANUDEM algorithm is implemented in ArcGIS software as a Topo to Raster method, which was used for building the DEM. For comparison, DEM was created using other 12 building methods, which are implemented in ArcGIS and Surfer software products:

- IDW;

- Kriging;

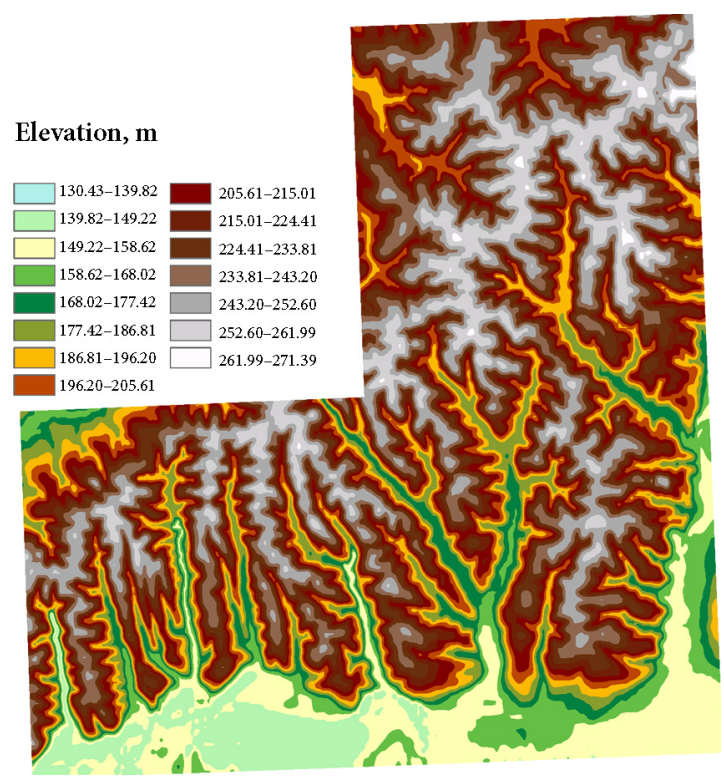

a) ANUDEM

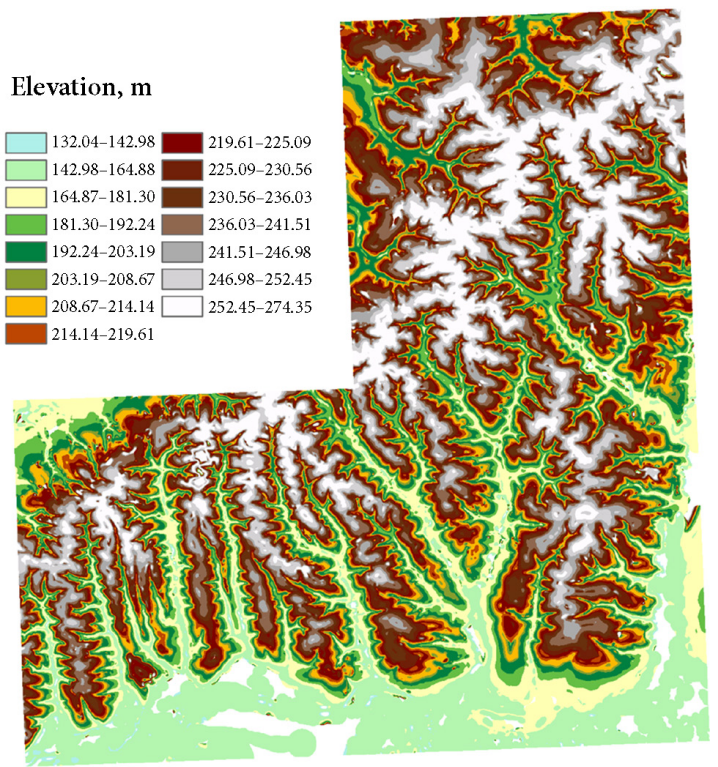

c) The Modified Shepard's Method
- Local Polynomial;

- Natural Neighbor;

- Nearest Neighbor;

- Radial Basis Function;

- Minimum Curvature;

- Modified Shepard's Method;

- Moving Average Method;

- Polynomial Regression Method;

- Triangulated Irregular Network (TIN);

- Triangulation with Linear Interpolation.

\section{Results}

The results of building with some of these methods are shown in Figure 13.

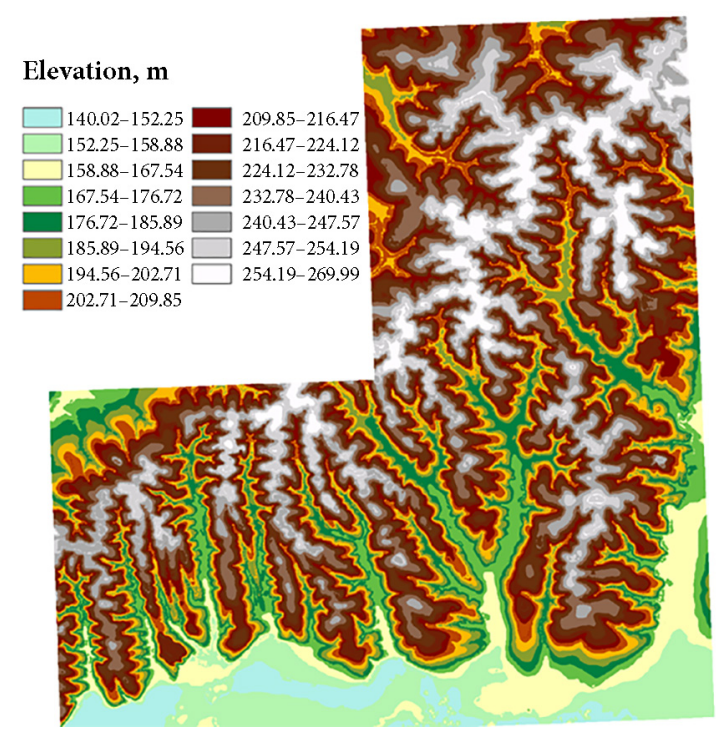

b) Inverse Distance Weighting

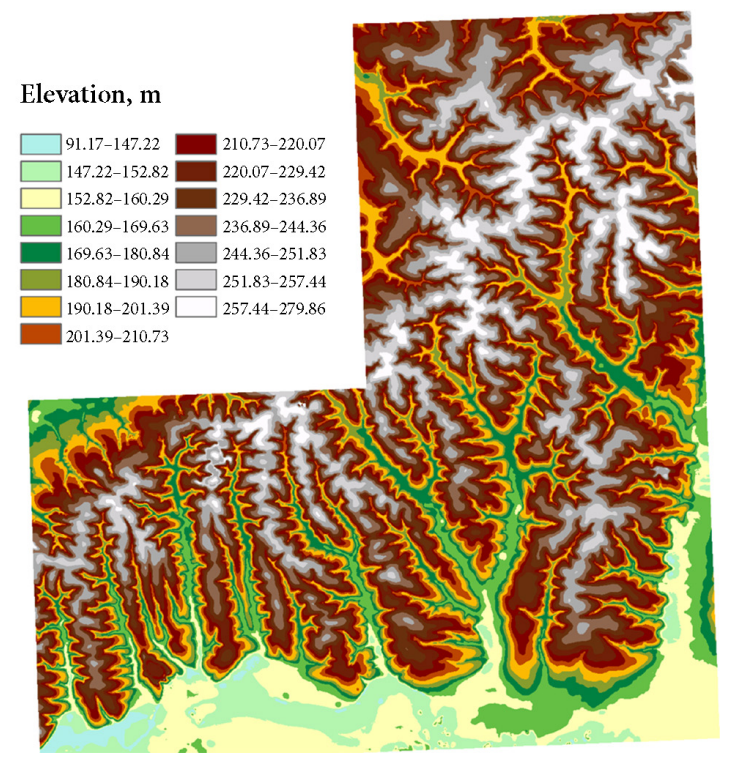

d) The Radial Basis Function

Figure 13. DEMs built using different interpolation methods 


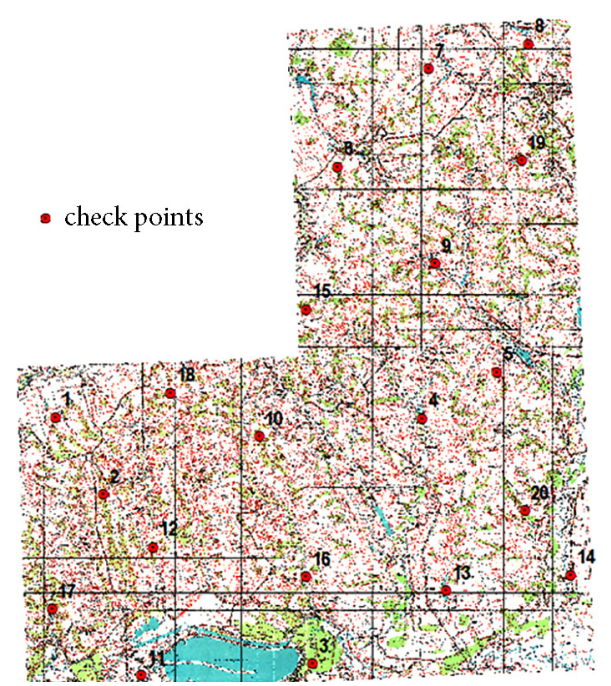

Figure 14. Check points layout

A description of the methods implemented in Surfer can be found, for example, in Yang et al. (2004).

Accuracy estimation for the results. In order to analyze the accuracy of the DEM built with each of the 13 interpolation methods, check points were used (Figure 14), which were selected with taking into account the peculiarities of the terrain and hydrographic network and were evenly distributed over the study area. The elevations of check points were determined by topographic maps. The values of elevation at check points were accepted as true, and RMSE of the elevation interpolation at these points were calculated by the Gaussian formula (Johnston et al., 2001):

$$
R M S E=\sqrt{\frac{\sum_{i=1}^{n}\left(X_{3}-\tilde{X}\right)^{2}}{n}},
$$

where $X_{i}$ is the elevation value obtained from the interpolated DEM, $\tilde{X}_{3}$ is the elevation value obtained from the

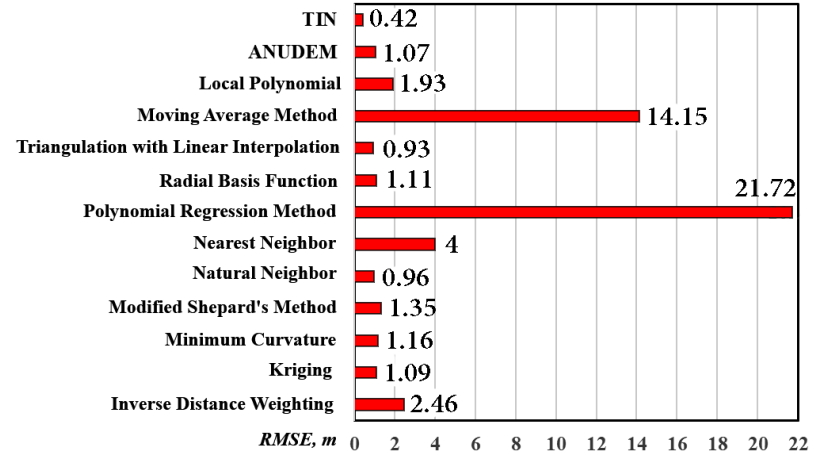

Figure 15. The results of estimating the accuracy of DEM interpolation methods

topographic map, $n$ - number of points $(n=20)$.

The results of RMSE calculations are shown in Figure 15.

In order to estimate the reliability of obtained RMSE values, the confidence interval method was used. As is known, the boundaries of the confidence intervals for the true value of the measured quantity and its RMSE are set depending on the given confidence probability and the law of error distribution. The confidence interval for the standard error in the case of a normal sample is as follows (Voitenko, 2003):

$$
\gamma_{1} m \leq \sigma \leq \gamma_{2} m
$$

where $m$ is the RMSE, $\sigma$ is the theoretical value of RMSE, and values of $\gamma_{1}$ and $\gamma_{2}$ can be obtained from tables or calculated by formulas: $\gamma_{1}=\sqrt{\frac{n-1}{\chi_{1}^{2}}}, \gamma_{2}=\sqrt{\frac{n-1}{\chi_{2}^{2}}}$.

Values of $\chi_{1}^{2}$ and $\chi_{2}^{2}$ are chosen from the tables of $\chi^{2}$ distribution by the number of degrees of freedom $(n-1)$ for the probability $p_{2}=0.5(1-\beta), p_{1}=1-p_{2}$, where $\beta$ is the confidence probability.

\begin{tabular}{|c|c|c|c|c|c|c|}
\hline Method & RMSE, $\mathrm{m}$ & $\begin{array}{l}\text { The lower limit } \\
\text { of the interval }\end{array}$ & $\begin{array}{l}\text { The upper limit } \\
\text { of the interval }\end{array}$ & $\begin{array}{l}\text { Estimation of } \\
\text { RMSE, } m\end{array}$ & $\begin{array}{l}\text { The lower limit } \\
\text { of the interval }\end{array}$ & $\begin{array}{l}\text { The upper limit } \\
\text { of the interval }\end{array}$ \\
\hline IDW & 2.46 & 1.85 & 3.59 & 0.55 & 0.41 & 0.8 \\
\hline Kriging & 1.09 & 0.83 & 1.6 & 0.24 & 0.18 & 0.36 \\
\hline Minimum Curvature & 1.16 & 0.88 & 1.7 & 0.26 & 0.2 & 0.38 \\
\hline $\begin{array}{l}\text { Modified Shepard's } \\
\text { Method }\end{array}$ & 1.35 & 1.02 & 1.97 & 0.3 & 0.23 & 0.44 \\
\hline Natural Neighbor & 0.96 & 0.72 & 1.4 & 0.21 & 0.16 & 0.31 \\
\hline Nearest Neighbor & 4 & 3.02 & 5.85 & 0.9 & 0.68 & 1.31 \\
\hline Polynomial Regression & 21.72 & 16.4 & 31.75 & 4.86 & 3.67 & 7.1 \\
\hline Radial Basis Function & 1.11 & 0.84 & 1.62 & 0.25 & 0.19 & 0.36 \\
\hline $\begin{array}{l}\text { Triangulation with } \\
\text { Linear Interpolation }\end{array}$ & 0.93 & 0.7 & 1.36 & 0.21 & 0.16 & 0.3 \\
\hline Moving Average & 14.15 & 10.69 & 20.69 & 3.16 & 2.39 & 4.63 \\
\hline Local Polynomial & 1.93 & 1.46 & 2.83 & 0.43 & 0.33 & 0.63 \\
\hline ANUDEM & 1.07 & 0.81 & 1.57 & 0.24 & 0.18 & 0.35 \\
\hline TIN & 0.42 & 0.31 & 0.61 & 0.09 & 0.07 & 0.14 \\
\hline
\end{tabular}

Table 1. Confidence interval boundaries 
After determining an interval, it is easy to obtain a confidence interval for the RMSE of a simple arithmetic mean by dividing all terms of the inequality by $\sqrt{n}$ :

$$
\gamma_{1} M \leq \sigma_{\bar{x}} \leq \gamma_{2} M
$$

where $M$ is the RMSE of a simple arithmetic mean, $\sigma_{x}^{-}$is its theoretical value.

Assuming the value of the confidence probability $\beta=0.95$ with $n=20$, we obtain: $p_{1}=0.025, p_{2}=0.975$, $\chi_{1}^{2}=33.32, \chi_{2}^{2}=8.89, \gamma_{1}=0.76, \gamma_{2}=1.46$. The results of the calculations are given in Table 1 .

Analyzing the confidence intervals, we see that, for all interpolation methods, the obtained values of RMSE and its estimations are within the confidence intervals.

\section{Conclusions}

The paper considers building a DEM by thirteen interpolation methods, both deterministic and geostatistical, in ArcGIS and Surfer software products. As a elevation matrix, we use contour lines obtained from soviet topographic maps at a scale of 1:50,000, which were digitized automatically using a program written in the Python programming language. The accuracy of the measurement of the original data is one of the key factors for building a DEM, along with the density of data, their distribution, DEM resolution, the interpolation methods used. Soviet topographic maps of scale 1:50,000 have the mean absolute error in the vertical position of contour lines relatively to the nearest points and the points of the geodetic base, according to regulations, which does not exceed $3.0 \mathrm{~m}$ for plains and rugged terrains with angles up to $6^{\circ}$, as for the studied territory. The error in digitizing the contour lines was excluded due to the use of the method of automatic vectorization.

When building a DEM by the ANUDEM method, in addition to the contour lines, other data about the relief of the study area were used: data of the hydrographic network, lakes, elevations and data of sink points.

For each of the built DEMs, an estimation of their accuracy was performed by calculating the RMSE at checkpoints. The TIN, Triangulation with Linear Interpolation, Natural Neighbor, ANUDEM methods were determined to have the lowest RMSE with the values of $0.42 \mathrm{~m}$, $0.93 \mathrm{~m}, 0.96 \mathrm{~m}$, and $1.07 \mathrm{~m}$, respectively. Confidence intervals were used to estimate the reliability of RMSE. All RMSE values are in the calculated intervals. At the same time, to determine the peculiarities of the river network and sink as well as for hydrological modeling, it is recommended to use DEMs built by the ANUDEM method, because it allows to obtain hydrologically correct DEMs.

\section{References}

Ajvazi, B., \& Czimber, K. (2019). Comparative analysis of different DEM interpolation methods in GIS: Case study of Rahovec, Kosovo. Geodesy and Cartography, 45(1), 43-48. https://doi.org/10.3846/gac.2019.7921
ANU Fenner School of Environment and Society and Geoscience Australia. (2008). GEODATA 9 second DEM and D8 digital elevation model and flow direction grid, user guide. Geoscience Australia, Canberra.

Arun, P. V. (2013). A comparative analysis of different DEM interpolation methods. The Egyptian Journal of Remote Sensing and Space Sciences, 16, 133-139. https://doi.org/10.1016/j.ejrs.2013.09.001

Curebal, I., Efe, R., Ozdemir, H., Soykan, A., \& Sönmez, S. (2015). Gis-based approach for flood analysis: Case study of keçidere flash flood event (Turkey). Geocarto International, 31(4), 355366. https://doi.org/10.1080/10106049.2015.1047411

EarthExplorer. (n.d.). Home. https://earthexplorer.usgs.gov/

Hutchinson, M. F. (1988). Calculation of hydrologically sound digital elevation models. In Proceedings of the $3 \mathrm{rd}$ International Symposium on Spatial Data Handling (pp. 117-133). Sydney, Australia.

Hutchinson, M. F. (1989). A new method for gridding elevation and stream line data with automatic removal of pits. Journal of Hydrology, 106, 211-232.

https://doi.org/10.1016/0022-1694(89)90073-5

Hutchinson, M. F., Stein, J. A., Stein, J. L., \& Xu, T. (2009, July 13-17). Locally adaptive gridding of noisy high resolution topographic data [Conference Proceedings]. 18th World IMACS / MODSIM Congress, Cairns, Australia.

Hutsul, T., \& Smirnov, Y. (2017). Comparative accuracy assessment of global DTM and DTM generated from soviet topographic maps for the purposes of road planning. Geodesy and Cartography, 43(4), 173-181.

https://doi.org/10.3846/20296991.2017.1412638

Johnston, K., VerHoef, J., Krivoruchko, K., \& Neil, L. (2001). Using ArcGIS ${ }^{\mathrm{Tm}}$ Geostatistical Analyst. ESRI ${ }^{\mathrm{Tm}}$, US.

Liashenko, D., Belenok, V., Spitsa, R., Pavlyuk, D., \& Boiko, O. (2020, November 10-13). Landslide GIS modelling with QGIS software. In XIVth International Scientific Conference on Monitoring of Geological Processes and Ecological Condition of the Environment. European Association of Geoscientists \& Engineers, Kyiv. https://doi.org/10.3997/2214-4609.202056069

Pivnyak, G. G., Busyigin, B. S., Korotenko, G. M., \& Korotenko, L. M. (2014). Anglo-russko-ukrainskiy slovar po GIS i DZZ: ucheb. posobie. Ministerstvo obrazovaniya i nauki Ukrainyi, Natcionalnyi gornyi universitet (In Russian).

Rul, N. V., Velikodsky, Yu. I., \& Zatcerkovnyi, V. I. (2018, May 14-17). The algorithm of automatic vectorization of contours for constructing digital elevation models [Conference Proceedings]. 17th International Conference on Geoinformatics: Theoretical and Applied Aspects. Institute of Geology of Taras Shevchenko Kyiv National University, Kyiv. https://doi.org/10.3997/2214-4609.201801840

Salari, A., Zakaria, M., Nielsen, C. C., \& Boyce, M. S. (2014). Quantifying tropical wetlands using field surveys, spatial statistics and remote sensing. Wetlands, 34, 565-574. https://doi.org/10.1007/s13157-014-0524-3

Salekin, S., Burgess, J. H., Morgenroth, J., Mason, E. G., \& Meason, D. F. (2018). A comparative study of three nongeostatistical methods for optimising digital elevation model interpolation. ISPRS International Journal of Geo-Information, 7(8), 300. https://doi.org/10.3390/ijgi7080300

Shihov, A. N., Cherepanova, E. S., \& Pyankov, S. V. (2017). Geoinformatsionnyie sistemyi: metodyi prostranstvennogo analiza: ucheb. posobie. Permskii gosudarstvennyi natcionalnyi issledovatelskii universitet (in Russian). 
Stein, J. L. (2006). A continental landscape framework for systematic conservation planning for Australian rivers and streams [PhD Thesis]. Centre for Resource and Environmental Studies, Australian National University.

Tagelsir, M. G. (2010). Handbook of research on hydroinformatics: Technologies, theories and applications. IGI Global.

Tan, Q., \& Xu, X. (2014). Comparative analysis of spatial interpolation methods: An experimental study. Sensors \& Transducers, 165(2).

United States Geological Survey. (n.d.). What are digital elevation models (DEMs)? https://www.usgs.gov/faqs/what-are-digitalelevation-models-dems?qt-news_science_products $=0 \#$ qtnews_science_products

Voitenko, S. P. (2003). Matematychna obrobka heodezychnykh vymiriv. Teoriia pokhybok vymiriv: Navchalnyi posibnyk. Kyivskyi natsionalnyi universytet budivnytstva i arkhitektury (in Ukrainian).

Wood, J. D. (1996). The geomorphologic characterization of Digital Elevation Models [PhD Thesis]. University of Leicester, Leicester, England.

Yakovchenko, S. G. (2007). Sozdanie geoinformatsionnyih sistem $v$ inzhenernoy gidrologii [PhD Thesis]. Barnaul (in Russian).

Yang, C. S., Kao S.-P., Lee, F. B., \& Hung, P.-S. (2004). Twelve different interpolation methods: A case study of Surfer 8.0. https://www.isprs.org/proceedings/xxxv/congress/comm2/ papers/231.pdf 